\title{
A GEOMORFOLOGIA PERANTE A CIÊNCIA GEOGRÁFICA: ALGUMAS REFLEXÕES
}

\section{Geomorphology in geographical science: some reflections}

António de Sousa Pedrosa

Universidade Federal de Uberlândia, Uberlândia, Minas Gerais, Brasil

Texto selecionado pata publicação em setembro de 2014.

RESUMO: O primeiro objectivo da Geografia é explorar e explicar o espaço geográfico. A ciência moderna necessita de um corpo teórico e não de uma obsessão de classificação, ou seja, existe a necessidade de um modelo epistemológico em que se defina teoricamente o seu objecto, trabalhe com conceitos e se estabeleça leis. Para que se compreenda a posição actual do geógrafo e, mais especificamente do geógrafo físico, é importante entender, como se processou evolução desta ciência e quais os conceitos fundamentais pelos quais ela se rege. Neste trabalho discute-se alguns problemas inerentes ao seu estatuto epistemológico pretendo-se contribuir para a compreensão de alguns conceitos e tendências evolutivas que estão na base da ciência geográfica e mais especificamente da Geografia Física. Pretende-se, igualmente, destacar a importância da Geomorfologia na formação de base de um geógrafo tendo como intenção provocar a reflexão e, ao mesmo tempo, suscitar uma tomada de consciência da relação que existe entre a formação teórica fundamental e a actividade prática futura dos geógrafos.

Palavras-Chaves: Geografia; Geomorfologia; epistemologia; conceitos; espaço geográfico.

ABSTRACT: The first aim of Geography is to explore and explain the geographic space. Modern science requires a theoretical rather than an obsession with classification, ie, there is a need for epistemological models that defines the theoretical objects, work with concepts and establish laws. In order to understand the current position of the geographer and more specifically the physical geographer, it is important to understand, how is the evolution of this science and what the fundamental concepts by which it falls.

In this paper we discuss some problems inherent in their epistemological status intend to contribute to the understanding of some concepts and changing trends, which are the basis of geographical science and more specifically of Physical Geography. The aim is also to emphasize the importance of geomorphology in the basic training of a geographer, and intended to provoke reflection and at the same time, raise an awareness of the relationship that exists between the fundamental theoretical and practical activity of the future geographers.

Keywords: Geography, Geomorphology, epistemology, concepts, geographical space. 


\section{INTRODUÇÃO}

O primeiro objectivo da Geografia é explorar e explicar o espaço geográfico. No entanto, afirmamos muitas vezes, mesmo entre geógrafos, que os tempos de exploração e de inventário são os tempos pré-científicos. A ciência moderna necessita de um corpo teórico e não de uma obsessão de classificação, ou seja, existe a necessidade de um modelo epistemológico em que ela defina teoricamente o seu objecto, trabalhe com conceitos, estabeleça leis e, a partir do momento que a lei esteja cientificamente provada pela teoria, passa-se à fase da verificação. É, assim, que se pode "verificar teoricamente as experiências" afirma Koyré (1982), não o inverso.

A Geografia entendida como ciência da Terra e dos Homens tem como objecto teórico o espaço, tem por conceito a escala, os pólos, a distância... e, tem por lei, por exemplo, a distribuição dos centros urbanos segundo uma hierarquia de serviços terciários. Estas leis explicam as configurações espaciais tipo e descrevem o funcionamento dos sistemas espaciais. A Geografia é, assim, indubitavelmente a ciência do espaço.

Para que se compreenda a posição actual do geógrafo e, mais especificamente do geógrafo físico, é importante entender, como se processou evolução desta ciência e quais os conceitos fundamentais pelos quais ela se rege. Neste trabalho se discute alguns problemas inerentes ao seu estatuto epistemológico e pretende-se contribuir para a compreensão de alguns conceitos e tendências evolutivas que estão na base da ciência geográfica e mais especificamente da Geografia Física. Pretende-se, igualmente, destacar a importância da Geomorfologia na formação de base de um geógrafo tendo como intenção provocar a reflexão e, ao mesmo tempo, suscitar uma tomada de consciência da relação que existe entre a formação teórica fundamental e a actividade prática futura dos geógrafos.

\section{A GEOMORFOLOGIA NO CONTEXTO DA CIÊNCIA GEOGRÁFICA}

O trabalho quotidiano de geógrafo não consiste em fazer uma teoria das leis do espaço, mas em intervir no espaço, para resolver os problemas que a sociedade lhe coloca. Perante esta perspectiva, a va- lidade de um juízo não advém da sua justeza teórica, mas da eficácia para resolver os problemas espaciais, sócio-económicos e ambientais que a própria sociedade coloca. Para isso, consulta todos os indicadores disponíveis, as fotografias aéreas, as imagens de satélite, documentos estatísticos e cartográficos e outras, elabora perfis topográficos, cortes geológicos, determina os perfis de alteração, reconstitui os paleo-ambientes..., e, por fim, estes resultados podem ser trnsmitidos às instâncias políticas responsáveis pelo ordenamento, de molde a que seja tomada uma decisão.

Deste modo, o geógrafo age mais como um naturalista do que como um teórico. Se existir uma lei no espaço, é a lei que irá decidir. Mas, o facto é que não existe. Para prever é necessário colher informação, hierarquizar os factores e propor uma escolha para a sociedade. É esta que comprovará, depois, a validade do trabalho do geógrafo como naturalista empírico.

Assim, o modelo epistemológico "objecto teórico, conceito e lei" (PECH et al.,1993), é nefasto para a Geografia por várias razões: razões de ordem teórica, já que no terreno não funciona; razões de ordem epistemológica, visto que muitas vezes se faz passar por investigação teórica a descrição matemática dos fenómenos.

Não é necessário escrever com números para estabelecer uma teoria. Uma lei estatística é justa em estatística. Não é senão por confusão que se pode dizer que o fenómeno que ela tenta medir é comandado pela lei. Pode ser que a lei descreva, convenientemente, o aspecto do fenómeno que se pretende prever, mas é necessário uma grande dose de platonismo para passar por teoria "jusque dans l'objet dont la théorie parle" (PECH et al.,1993). Já no século XVI, Guillaume d'Okman explicita bem o problema, ao afirmar que "o que é verdade num pensamento não é verdade da coisa pensada" (D'OKMAN apud PECH et al.,1993). Apesar de teoricamente justo um hidrograma de cheia, o conceito de cheia não se altera, só pelo facto de estar gráfica e estatisticamente representado. A cheia, per $s e$, não é teoria. Os seus efeitos não são descritos pela lei, mas são avaliados pelo controle dos especialistas;

Por fim, existe outra razão pela qual se suspeita que as teorias sobre o espaço podem ser nocivas: esta razão é política. 
A teoria é incapaz de falar do meio geográfico. No entanto, isto não significa que o aparelho matemático se mostre incompleto ou que a inteligência artificial esteja ainda nos seus primeiros passos. De facto, a razão é mais profunda: é a que a teoria pretende ter/ ser razão. Ora esta razão teórica é aquela que todos os filósofos pós-totalitários se têm esforçado por destruir. Habermas (1997) diz que " $n$ 'est rien d'autre que $d u$ pouvoir, rien d'autre que cette volonté de puissance pervertie qu'elle recouvre avec tant de brio". Isto é grave porque o meio geográfico é construído por todas as sociedades e por todos os processos naturais. Dizer que o espaço possui leis é estabelecer que existem leis que a sociedade ou a natureza devem seguir para criar o espaço. É dar aos geógrafos que conhecem essas leis o enorme poder de dirigir a sociedade para lhe mostrar o que ela deve fazer do espaço. É privar a instituição política do direito de planear o seu quadro de vida. É, por fim, um desvio platónico "celle de roi géographe" (PECH; REGNAULD, 1993).

Assim sendo, recusamo-nos a ser naturalistas e teóricos. Tentaremos fazer parte das coisas: a Geografia mede, utiliza as leis, elabora algumas para prever os efeitos dos diferentes processos, já que pensamos que é possível apreender teoricamente cada um dos processos e as suas inter-relações. Neste aspecto, a Geografia apresenta as características de uma ciência pura e dura. Pensamos, no entanto, que o conjunto de todos os processos e as suas inter-relações criam um espaço sem leis. O espaço não possui leis abstractas para opor ao trabalho dos homens. Ele não é senão uma construção submetida aos jogos sociais e ecológicos (Figura 1). O espaço é dinâmico, percorrido de fluxos de energia, de lutas, de intervenções... Ele é produzido pelos processos sociais e naturais em interacção.

Os processos podem, por sua vez, ser influenciados e, quantas vezes, modificados, pela actuação do homem (erosão de solos, dinâmica fluvial, alterações climáticas....), razão ainda mais forte para que, a Geografia Física reforce a sua posição, no âmbito da ciência geográfica. De facto, se a erosão é um processo natural, torna-se cada vez mais uma produção social (MUXART et al. 1990). O termo naturalista toma então um sentido preciso já que, não pode ser entendido como uma valorização religiosa da mãe natureza, nem uma submissão mais ou menos suspeita aos valores da Terra (PECH; REGNAULD, 1993).

Figura 1. A produção do espaço geográfico.

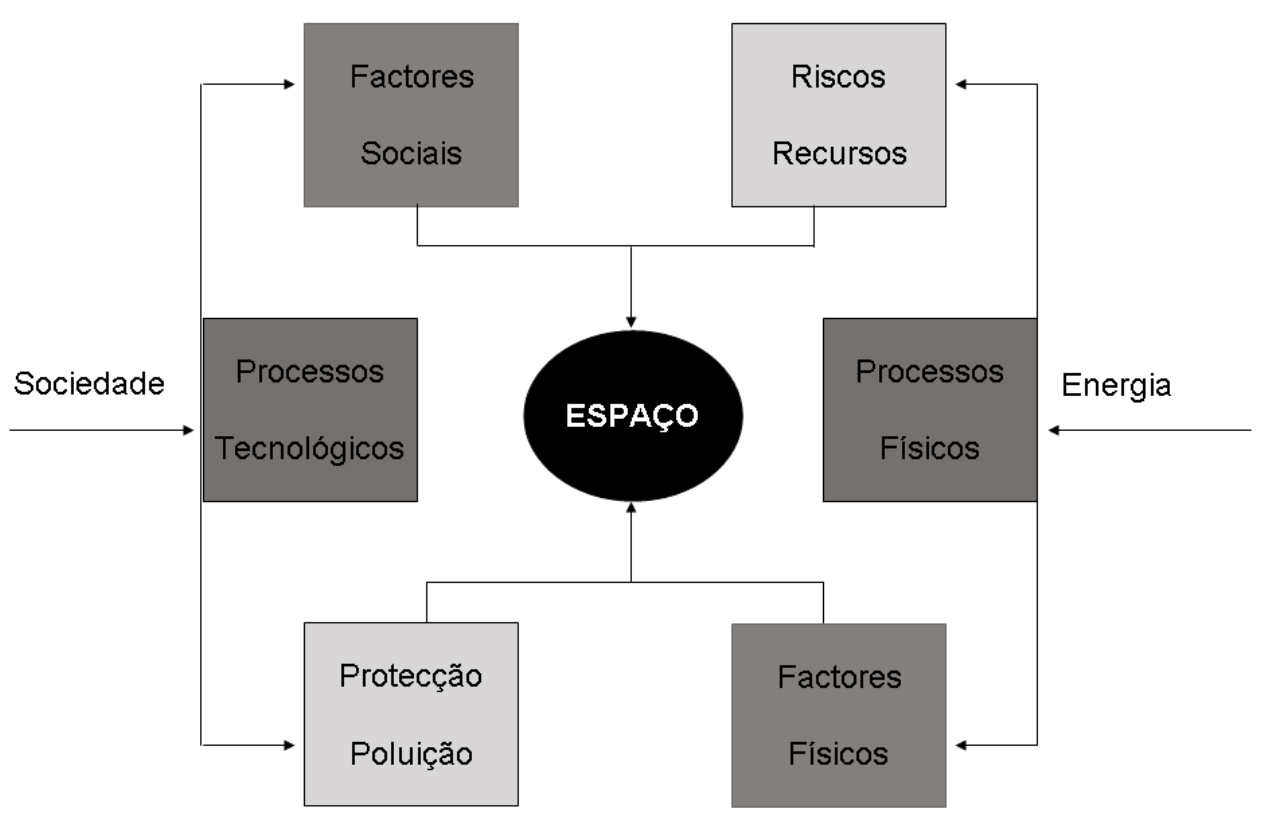

Fonte: Adaptado de P. Pech e H. Regnauld (1993). 
É dentro deste pressuposto que a Geomorfologia é importante no contexto da ciência geográfica, já que os processos físicos são, em parte, responsáveis pela dinâmica do espaço, razão por si só suficiente para que a Geografia não os possa ignorar.

Todavia, os processos físicos são capazes de influenciar o comportamento das sociedades, pelo que, tudo o que diz respeito às questões ambientais, deveria ser sempre cuidadosamente por nós encarado e estudado, com honestidade, na perspectiva da realização do objectivo principal que é a própria sobrevivência do homem e que, na prática, nem sempre acontece. E isto porque, em vez de se encarar de forma global, toda a humanidade, em termos espaciais ou terrestres, intemporais, cósmicos ou universais, consideram-se os problemas em termos limitados de espaço e de tempo, quase sempre com enorme egocentrismo, que se resume ao tempo restrito da vida da família, quando não pessoal.

Estas duas concepções, globais ou abrangentes, localizadas ou restritas, distinguem duas perspectivas contraditórias de gestão do ambiente que, afastadas pela filosofia dominante na sociedade da Revolução Industrial, estão condenadas pelo próprio homem a caminhar para a reconciliação.

Pode-se, então, dizer que, no decurso do tempo, até há poucos séculos, o comportamento da humanidade se baseava numa perspectiva natural, sistémica ou ecológica de perpetuidade, pouco dependente das intervenções, sempre superficiais, do homem de então. Só há pouco se iniciou uma outra fase que se fundamenta numa intervenção profunda e cada vez mais activa, de curto prazo, circunstancial e descuidada, e que deixou de ter em conta as regras ou princípios naturais que se baseavam na identidade e na estabilidade e, como tal, na perpetuidade dos recursos do mundo em que vivemos. Ainda, hoje, a maior preocupação incide apenas no crescimento das coisas, no aumento de lucro das empresas e no reforço das economias.

Nesta segunda fase, podemos afirmar que a intervenção agressiva do homem se caracteriza por criar desvios ou disfunções de maior ou menor amplitude àquilo que podemos considerar normal, às marcas recebidas por herança de gerações anteriores ou adquiridas por mutações relativamente circunstanciais.
As causas mais frequentes relacionam-se ao regime alimentar, às deslocações cada vez mais constantes, ao conforto material exagerado e luxuoso e às condições de trabalho em ambiente desgastantes que, pelo cansaço físico e mental, levam à angústia que atinge o equilíbrio do sistema.

Percebe-se, portanto, que o estudo das relações/interacções entre as necessidades (ou exigências) do hóspede - o Homem - que acabamos de referir, e as reservas dos materiais armazenadas na dispensa da hospedaria ou do hospedeiro - a Terra - deveriam fazer parte dos vários níveis de ensino, com o intuito de divulgar o conhecimento o que permitiria a sua assimilação e interiorização e, como tal, ao respeito pela natureza e por todas as questões ambientais. Não sendo assim, gera-se uma situação de conflito pelo comportamento do elemento mais activo e menos conformado, que é o hóspede, o que dificulta a manutenção do sistema, em equilíbrio dinâmico que se desejaria perpétuo ou sustentável (MARSH et al., 2001). A palavra "sustentável" faz hoje parte do léxico e dos discursos dos profissionais de economia e da política embora se saiba que nem sempre as suas acções e actuações estejam de acordo com o seu significado mais profundo.

É evidente que, nos dois últimos séculos, devido à filosofia judaico-cristã do Norte da Europa, responsável pelo grande surto de tecnologia e do crescimento material, a capacidade física de intervenção do homem no ambiente foi multiplicada por factores tão elevados quanto imprevisíveis. Foi uma situação que permitiu a revolução urbana e industrial e o aumento, até então inconcebível, da produção, do consumo e da riqueza de alguns. Compreende-se que, na situação de antagonismo Ambiente/Homem que se acentuou com este novo modo de vida, se tenha traçado caminhos cada vez mais divergentes e conflituosos entre os interesses do Homem e os do Ambiente. No Planeta Terra, tudo se interliga e a capacidade de recuperação e reciclagem que, até bem pouco tempo, acreditava-se inesgotável, já demonstrou de forma evidente as suas limitações, começando-se a atingir em todo o sistema pontos de ruptura (BAILLY; FERRAS, 1997).

Assim, o ambiente não pode ser reduzido a uma questão de poluição, de ruído, de resíduos sólidos, de esgotos e de abastecimento de águas, como preten- 
dem alguns negociantes do ordenamento, em nome do crescimento, ou do urbanismo, em nome da modernidade, ou da industrialização, em nome da criação ou da salvação de postos de trabalho. $\mathrm{O}$ ambiente deve ser encarado em toda a sua complexidade e o homem, ao perseguir o seu ideal de uma melhor qualidade de vida, tem de compreender que só potenciando a diversidade (social, cultural, biológica, ambiental...) pode chegar a um desenvolvimento equilibrado, conduzindo a uma maior valia da natureza e do próprio ser humano. $\mathrm{O}$ Homem, enquanto agente da mudança na Natureza, cria a paisagem, dando-lhe forma, força, matéria e funcionalidade, em que ela própria exige ser um espaço continuum de diversidade, combatendo, desta maneira, a própria simplificação e uniformização da Natureza. A história da humanidade é, em larga medida, a história da nossa relação com a natureza das mudanças, das crises, dos paradigmas, das visões do Mundo que se foram sucedendo (DERRUAU, 1996).

Pode afirmar-se que as relações entre o homem e a morfogénese se desenvolvem segundo três pontos de vista. Um primeiro será a consciencialização do poder efectivo que possui sobre a evolução da morfogénese que o levará a interrogar-se sobre a natureza das relações ao nível de processos elementares e das suas mais diversas combinações. Um outro surge quando, ao tomar conhecimento do funcionamento do sistema, o ser humano sente a necessidade de saber como a sua actuação influencia os factores naturais e, daí, os processos morfogenéticos. Por último, nunca se poderá esquecer que a erosão que o homem exerce não é uma entidade abstracta, antes pelo contrário, é uma realidade multiforme (NEBOIT, 1991).

A diversidade das situações regionais sujeita a riscos diferenciados leva a que se questione se o equilíbrio natural pode ou não ser controlado. Nesta desigualdade de tratamentos, coloca-se o problema da relatividade do peso dos factores naturais e o dos factores humanos. Enfim, é preciso encarar este fenómeno sob diversas escalas temporais (NEBOIT, 1991). A presença do homem na Terra é o resultado de um compromisso dinâmico entre as suas necessidades fisiológicas e culturais e a exploração dos recursos naturais existentes, mas a vida transcende largamente a espécie humana - que é, apenas, uma das espécies existentes, a mais recente e, porventura, uma das mais vulneráveis. Ao longo da história do Planeta, constata-se que o homem não é o primeiro ser vivo a modificar o meio ambiente ou a provocar alterações climáticas: há muitos milhões de anos, as algas marinhas modificaram profundamente a composição da atmosfera, libertando oxigénio, que constituiu um veneno letal para os microrganismos com metabolismo sulfuroso, que existiam ao ar livre. Este facto prova que a evolução progressiva, de efeitos cumulativos, mais cedo ou mais tarde atinge um ponto de ruptura, já que, na natureza, não existe crescimento contínuo. O mesmo pode acontecer com o homem, se continuar, como nos últimos séculos, a agredir o ambiente, ao contrário da sua inicial posição de defesa pela sua própria sobrevivência (PEDROSA, 1997).

\section{O CONHECIMENTO GEOMORFOLÓGICO E SUA IMPORTÂNCIA PARA A MANUTENÇÃO DO EQUILÍBRIO DINÂMICO DOS SISTEMAS TERRESTRES}

A geomorfologia entendida como o estudo científico das formas de relevo da superfície da Terra é, sem dúvida, como dizia J. Tricart (1965), uma das peças mestras da ciência geográfica. Assim, sempre que se pretenda uma completa explicação de qualquer forma da Terra, há que se fazer uma descrição da sua figura geométrica e compreender os processos envolvidos na sua génese, bem como no seu desenvolvimento através do tempo.

Não basta a simples descrição das formas de relevo, torna-se fundamental o conhecimento das características climáticas da região em causa, bem como o conhecimento das características tectónicas, litológicas e biogeográficas, para compreender os processos morfogenéticos.

Assim ter-se-á de salientar a importância que os factores estruturais, nomeadamente a tectónica e a litologia, possuem na génese e evolução das formas de relevo, assim como a influência, que possuem na génese dos processos morfogenéticos. (FEIO; BRITO, 1949; BLÉS; FEUGA, 1981; OOLIER, 1981). Por exemplo, o factor litológico relaciona-se com a maior ou menor dureza das rochas, reflexo da sua génese e das suas características químico-mineralógicas. Deste modo, há determinadas formas que se relacionam sem 
qualquer margem para dúvidas com os diferentes tipos de rochas, tornando-se necessário conhecer o seu comportamento em função dos processos actuantes ( GODARD, 1977; REBELO, 1975, 1991; TWIDALE, 1982, 1989; VALADAS, 1984; ROMANI, 1984; CUNHA, 1988; PEDROSA, 1993). Mas não se pode colocar de parte todas as interacções que existem com o comportamento dos solos e com a vegetação, já que estes condicionam de forma indubitável a existência e comportamento de diversos processos morfogenéticos.

O estudo do meio físico, como objecto geográfico, é cada vez mais importante e necessário ao próprio homem, pois foi, ao longo dos tempos históricos, e continuará a ser, o suporte das sociedades e das actividades humanas (PEDROSA, 1994; SLAYMAKER, 2000). O suporte físico dos territórios, tanto pode constituir um risco como se pode apresentar frágil. O seu estudo e, por conseguinte, a compreensão do seu dinamismo leva, certamente, a uma gestão mais racional e quiçá mais correcta do território, cujo objectivo final será não só prever os perigos, mas também, desenvolver sistemas de resiliência que se julguem necessários, como, por exemplo:

-protecção das populações contra diferentes catástrofes naturais (sismos, fenómenos vulcânicos, ciclones tropicais, inundações...);

-protecção das diferentes formas de poluição ou formas de degradação desse meio, nomeadamente dos seus recursos naturais (RAMADE, 1987; REBELO, 1994; BOURRELIER et al., 2000; STRAHLER, 2001).

Os objectos geográficos são todos os fenómenos que têm expressão no espaço. Os meios naturais e os fluxos naturais são, então, objectos geográficos de corpo inteiro.

Estes sistemas naturais auto-organizados (BAK; CHEN, 1991) são constituídos por elementos estáveis (litosfera, atmosfera, hidrosfera, biosfera, antroposfera) que se encontram em interrelação através dos fluxos de energia e de matéria que circulam entre eles.

Estão, também, organizados pela convergência de forças e de processos aleatórios e contraditórios que levam a estádios momentaneamente equilibrados. É o caso das vertentes de montanha "ordenadas" pelo homem que conhecem uma estabilidade aparente, apesar de um dado número de factos e fenómenos, como o forte declive ou a precipitação elevada, serem favoráveis à instabilidade. Contrariamente, certos processos naturais possuem uma variação periódica que se pode considerar normal (escoamento fluvial, marés...). No entanto, nesta aparente regularidade, podem surgir crises que conduzam a um comportamento caótico e desordenado da natureza (uma cheia, por exemplo). Podem existir, ainda, elementos que levem ao aparecimento de estádios críticos instantâneos, conduzindo a situações de risco grave. Estão neste caso os sismos, os vulcões, os ciclones tropicais entre outros.

A precisão com a qual se pode prever a evolução de um sistema dinâmico depende da precisão com que se conhecem as suas condições iniciais e as leis da sua dinâmica (GLEICK, 1987; WEBER et. al., 1996).

Deste modo, os estudos de geomorfologia têm-se debruçado sobre os processos morfogenéticos ( BIROT, 1981; GODARD; RAPP, 1987; REBELO, 1988, 2003; LOURENÇO, 1988; WEBER et. al., 1996). Este interesse fica a dever-se a diversas razões.

A razão principal prende-se com o próprio objecto de estudo desta ciência, isto é, as formas da superfície da Terra (PITTY, 1971), entendidas como o resultado de uma dinâmica em que os intervenientes são múltiplos e as relações complexas. Depreende-se, então, que o estudo tem de possuir uma perspectiva morfodinâmica onde se interrelacionam as formas, os processos morfogenéticos passados, assim como aqueles que, actualmente, são responsáveis pela evolução das formas de relevo.

De facto, é importante conhecer como uma determinada área evoluiu no passado, pois pode ter capacidade para influenciar de uma forma muito directa a evolução actual (BOARDMAN, 1985; PEDROSA, 1993, 1994; EDDY et al., 1993; REBELO, 2001; PEDROSA et. al., 1997). Também o conhecimento como actuam na actualidade os diversos processos, pode ajudar a clarificar a maneira como se processaram no passado. Na verdade, hoje apenas podem ser deduzidos pelas formas que originaram e pelos vestígios que deixaram. Tal como escreveu F. Rebelo (1981), é o estudo dos processos morfogenéticos actuais que possibilita o conhecimento do modo como evoluem as formas de relevo no seu conjunto e a uma escala 
suficientemente vasta. O seu estudo, todavia, tem de ser feito a uma escala cada vez mais pormenorizada, no sentido de conhecermos os seus vários aspectos e as suas implicações, principalmente sobre as construções humanas, mas também sobre os custos sociais e económicos.

Trata-se, no entanto, de um trabalho complexo já que um sistema morfogenético não se reduz a uma simples soma de processos elementares. É necessário concebê-lo numa perspectiva dinâmica, ou seja, como um sistema de inter-relações entre os processos dominantes e os não dominantes, segundo um jogo de factores que eles próprios controlam (TRICART; CAILLEUX, 1965).

É este tipo de relações que o geomorfólogo terá de identificar e conhecer para formular alternativas que possibilitem ao homem uma melhor utilização do território quer nos aspectos de ocupação propriamente dita, quer no uso das técnicas que melhor se adequem à exploração do mesmo (MAHENDRARAJAH, et al., 1999). Assim, pode contribuir para a manutenção do equilíbrio dinâmico das formas de relevo e evitando, também, a degradação, por vezes rápida, dos solos, o que é muito importante para a prática agro-florestal, por exemplo.

\section{CONCLUSÃO}

Dentro desta perspectiva, a Geomorfologia pode proporcionar uma reflexão séria sobre questões que continuam a fazer parte do nosso quotidiano, abrindo novos cenários científicos, culturais e sociais que proporcionem à sociedade uma visão diferente, sobre o próprio espaço em que se insere. Desta forma, é no ordenamento do território que o contributo da geomorfologia pode ter uma aplicação prática, colocando à disposição da sociedade o conhecimento adquirido.

$\mathrm{Se}$, de facto, entendermos o ordenamento do território como um conjunto de acções localizadas, num dado espaço, visando realizar uma optimização da sua utilização, então não se pode esquecer que este espaço possui uma dimensão física, natural. Assim, o ordenamento do território tem como base o conhecimento das formas de relevo e das características climáticas, hidrológicas e biogeográficas da região, objectos de estudo da Geografia. Por isso, sem embargo de encontrarmos o geógrafo numa fase adiantada dos trabalhos de ordenamento de modo a distinguir as insuficiências e desequilíbrios de uma região, tendo em vista suprimi-las e modificar a paisagem, teremos sempre de o encontrar na fase inicial, no momento da definição dos suportes físico-naturais (REBELO, 1994).

A condenação sistemática das acções antrópicas sobre o meio não se justifica. O progresso que marcou o desenvolvimento das sociedades impôs-se, através da apropriação da natureza e, sem dúvida, este facto continuará a verificar-se. Apenas, no nosso entender, não é admissível a sua sobre-exploração e "gestão" incontrolada, como as gerações de um passado recente o fizeram e, ainda, o continuamos a fazer. As gerações vindouras terão necessidade da natureza para continuar a apoiar o seu desenvolvimento. Cabe à geração actual iniciar uma gestão controlada das acções sobre essa mesma natureza no sentido de preservar o que é de preservar e de recuperar aquilo que ainda é recuperável e, sobretudo, deixar, definitivamente, de agredir, essa mesma natureza, de forma tão destrutiva (PEDROSA, 1997).

E. Morin (1991) insistiu na existência de uma disjunção fundamental entre o homem e o mundo físico ou natural. Considera que o homem criou um estatuto de insularidade, tentando divorciar-se do seu suporte natural. É claro que uma tal situação é insustentável e a investigação geográfica deve, como já o vem fazendo, integrar nos seus estudos as relações homem-meio.

O geógrafo deve estar preparado para entender as interacções existentes no nível da superfície da Terra (estrutura, formações superficiais, pedologia, hidrologia, ocupação florestal, ocupação agrícola, ocupação urbana...), de modo a poder intervir na identificação dos problemas, na interpretação das ocorrências em termos espaciais e temporais e na formalização de suportes gráficos e cartográficos com utilidade para o planeamento.

\section{REFERÊNCIAS}

BAILLY, A.; FERRAS, R. Élements d'épistémologie de la Géographie. Paris : Armand Colin, 1997. 
BAK, P.; CHEN, K. Les systémes critiques auto-organisés. Pour la science, $\mathrm{n}^{\circ}$ 161, p. 52-60, 1991.

BIROT, P. Les processus d'érosion à la surface des continents. Paris: Masson, 1981.

BLÈS, J.; FEUGA, B. La fracturation des roches. Orléans: BRGM, 1981.

BOARDMAN, J. Soils and quaternary landscape evolution. New York: John Wiley \& Sons, 1985.

BOURRELIER, P. H. et al. Les catastrophes naturelles: le grand cafouillage. Paris: Osman Eyrolles Santé \& Société, 2000.

CUNHA, L. As Serras Calcárias de Condeixa-Sicó-Alvaiázere. Estudo de Geomorfologia. Tese (Doutorado em Geografia). Coimbra: Faculdade de Letras da Universidade de Coimbra, 1988.

DERRUAU, M. (Dir.). Composantes et concepts de la géographie physique. Paris: Armand Colin, 1996.

EDDY J. A. et al. Global Changes in the Perspective of the Past. New York: John Wiley \& Sons, 1993.

FEIO, M.; BRITO, R. S. Les vallés de fracture dans les modèlé granitique portugais. In: CONGRÉS INTERNATIONALE DE GEOGRAPHIE. Lisboa, 1949. Anais... tomo II, p. 254-262, Lisboa, 1949.

GLEIK, J. La théorie du chaos, vers une nouvelle science. Paris: Flammarion, 1987.

GODARD, A. Pays et paysages du granite. Paris: PUF, 1977.

GODARD, A.; RAPP, A. Processus et mesure de l'érosion. Paris: CNRS, 1987.

HABERMAS, J. Sur le droit et la démocratie. Note pur un débat. Le Débat, Paris, nº 97, Nov./Dez, 1997.

KOYRÉ, A. Estudos de História do Pensamento Científico. Rio de Janeiro: Editora Forence Universitária, 1982.
LOURENÇO, L. Efeitos do temporal de 23 de Junho de 1988 na intensificação da erosão das vertentes afectadas pelo incêndio florestal de Argil/Oliveira de Hospital. In: SEMINÁRIO TÉCNICO - PARQUES E CONSERVAÇÃO DA NATUREZA NOS PAÍSES DO SUL DA EUROPA. Comunicações e conclusões do Seminário Técnico - Parques e Conservação da Natureza nos Países do sul da Europa. Faro, p. 4377, 1988.

MAHENDRARAJAH S. et al. Modelling Change in Integrated Economic and Environmental Systems. New York: John Wiley \& Sons, Inc, 1999.

MARSH, W.M. et al. Environmental Geography: Science, Land Use and Earth Systems. $2^{\mathrm{a}}$ ed. New York: John Wiley \& Sons, Inc, 2001.

MORIN, Edgar. $O$ método. Vol.1. A natureza da natureza. Lisboa: Publicações Europa-América, 1991.

MUXART, T. et al. L'érosion sur les hautes du Lingas: un processus naturel, une production sociale. Paris: CNRS, 1990.

NEBOIT, R. L'Homme et l'érosion. L'érosion des sols dans le monde. 2 ed. Clermont-Ferrand : Faculté des Lettres et Sciences Humaines de l'Université Blaise-Pascal, 1991.

OOLIER, C. D. Tectonics and Landforms. London: Longman, 1981.

OOLIER, Cliff. Weathering. Edinburgh: Olivier \& Boyd, 1969.

PECH, P.; REGNAULD; H. Géographie physique. Paris: PUF, 1993.

PEDROSA, A. S. Serra do Marão: Estudo de geomorfologia. Tese (Doutorado em Geografia). Faculdade de Letras da Universidade do Porto. Porto, 1993.

PEDROSA, A. S. As actividades humanas e os processos morfológicos. O exemplo da Serra do Marão. Territorium, Coimbra, p. 23-34, 1994. 
PEDROSA, A. S. Geografia Física, Ambiente e Ordenamento do Território, que perspectivas?, Cadernos ESAP 1. Porto, p. 7-13, 1997.

PITTY, A. Introdution to Geomorphology. Londres: Methuen, 1971.

RAMADE, F. Les catastrophes écologiques. Paris: McGraw-Hill, 1987.

REBELO, F. Serras de Valongo. Estudo de geomorfologia. Suplementos de Biblos. Coimbra, nº 09, 1975.

REBELO, F. Introdução ao estudo dos processos erosivos actuais na região do norte e do centro de Portugal, Revista da Universidade de Coimbra. Coimbra, 29, p. 85-95, 1981.

REBELO, F. A problemática da quantificação dos processos morfogenéticos. Alguns aspectos da contribuição da Escola de Geografia de Coimbra. Cadernos de Geografia. Coimbra. nº 7, p. 137-143, 1988.

REBELO, F. Do ordenamento do território à gestão dos riscos naturais. A importância da Geografia Física salientada através de casos seleccionados em Portugal. Territorium. Coimbra, p.7-15, 1994.

REBELO, F. Riscos naturais e acção antrópica. Coimbra: Imprensa da Universidade, 2001.

REBELO, F. Riscos Naturais e Acção Antrópica. Estudos e Reflexões. $2^{\mathrm{a}}$ ed. Coimbra: Imprensa da Universidade de Coimbra, 2003.

ROMANI, J. R. V. Micromodelado de rocas graníticas. Un nuevo modelo genético. In: I CONGRESSO ESPAÑOL DE GEOLOGIA. Segóvia, 1984. Anais... Tomo I, Segóvia, p. 585-594, 1984.

SLAYMAKER, O. Geomorphology, Human Activity and Global Environmental Change. New York: John Wiley \& Sons, Inc, 2000.

STAHLER, Alan H. Physical Geography: Science and Systems of the Human Environment. 2a ed. New York:
John Wiley \& Sons, Inc, 2001.

TRICART, J. Principes te méthodes de la Géomorphologie. Paris: Masson, 1965.

TRICART, J.; CAILLEUX, A. Introdution à la géomorphologie climatique. Paris: Sedes, 1965.

TWIDALE, C. R. Granite landforms. Amsterdam: Elsevier, 1982.

VALADAS, B. Les hautes terres du massif Central Fançais. Contribution à l'étude des morphodynamiques récentes sur versants cristallins et volcanique. Vol. I, II, Paris, Université de Paris I, 1984.

WEBER, W.J. et al. Process Dynamics in Environmental Systems. New York: John Wiley \& Sons, 1996. 